\title{
Effects of exercise training on Fetuin-a in obese, type 2 diabetes and cardiovascular disease in adults and elderly: a systematic review and Meta-analysis
}

\author{
Robinson Ramírez-Vélez ${ }^{1 *} \mathbb{D}$, Antonio García-Hermoso ${ }^{2}$, Anthony C. Hackney ${ }^{3}$ and Mikel Izquierdo ${ }^{4}$
}

\begin{abstract}
Background: Elevated levels of fetuin-A are associated with increased risks of metabolic syndrome, type 2 diabetes and nonalcoholic fatty liver disease. This meta-analysis investigated whether exercise interventions can reduce fetuin-A in adults.

Methods: We searched clinical trials that objectively assessed fetuin-A and included study arms with exercise intervention. The pre-intervention and post-intervention data were used for meta-analysis. The effect sizes were calculated as standardized mean differences or changes in fetuin-A and expressed as Hedges' $\mathrm{g}$ using randomeffects models.

Results: The overall Hedges' g for fetuin- $\mathrm{A}$ in all included interventions was $-0.640(95 \% \mathrm{Cl}-1.129$ to $-0.151 ; n=$ 9), but this effect was not observed in obese ( $\mathrm{g}=-0.096 ; 95 \% \mathrm{Cl},-0.328$ to 0.135$)$ and type 2 diabetes/dysglycemia ( $g=-0.56 ; 95 \% \mathrm{Cl},-1.348$ to 0.236$)$ individuals. Additionally, the random-effects meta-regression analysis showed that there was not a greater decrease in fetuin- $A$ in individuals who achieved greater body mass index reductions (regression coefficient $=0.065 ; 95 \% \mathrm{Cl},-0.185$ to 0.315 ).

Conclusion: Supervised exercise is associated with reductions in fetuin-A levels in adults and elderly. However, the results of the present meta-analysis should be interpreted with caution because of the variety of type of exercises and individual obesity related-disorders involve. Therefore, additional high-quality randomized controlled trials describing the effect of supervised exercise interventions on fetuin-A in adults are still needed.
\end{abstract}

Keywords: Fetuin-a, Obesity, Type 2 diabetes, Metabolic syndrome, Cardiovascular disease, Exercise training, Metaanalysis, Systematic review

\section{Background}

Human fetuin-A (formerly named $\alpha 2$-Heremans-Schmid glycoprotein) is a $64-\mathrm{kDa}$ glycoprotein that is found in relatively high concentrations in serum $(300-1000 \mu \mathrm{g} / \mathrm{ml})$ [1]. Fetuin-A is mainly expressed and secreted from the liver and adipose tissue [2]. Recent studies suggest that the liver may control whole-body energy homeostasis through the regulation of glucose and lipid metabolism by

\footnotetext{
*Correspondence: robin640@hotmail.com; robinson.ramirez@urosario.edu.co ${ }^{1}$ Centro de Estudios para la Medición de la Actividad Física CEMA, Escuela de Medicina y Ciencias de la Salud, Universidad del Rosario, Bogotá 111221, Colombia

Full list of author information is available at the end of the article
}

the secretion of fetuin-A [3, 4]. For example, in an animal model of diet-induced obesity that is commonly associated with hepatic steatosis, an increase in fetuin-A mRNA expression was observed in the liver [4]. Cross-sectional $[5,6]$ and large cohort studies $[7,8]$ have demonstrated consistently that elevated fetuin-A levels are associated with increased risks of subclinical and clinical cardiovascular disease (CVD).

Circulating levels of fetuin-A are increased in obesity and related disorders such as the metabolic syndrome, type 2 diabetes, and myocardial infarction/stroke [9-12]. Fetuin A stimulates the production of pro-inflammatory cytokines from adipocytes and macrophages [13] and 
acts as an endogenous ligand for Toll-like receptor 4, which enables free fatty acids to activate Toll-like receptor 4 signaling to induce insulin resistance [14]. Moreover, fetuin-A levels is also associated with type 2 diabetes risk [9] due to been shown to inhibit skeletal muscle insulin receptor tyrosine phosphorylation and reduce Akt activity, which in turn, contributes to decreased peripheral glucose uptake [15]. Interestingly, this liver-derived protein is also associated with fatty liver and correlates with non-alcoholic fatty liver disease (NAFLD) in humans [16].

Recent research studies have investigated the mechanisms that underlie the relationship between fetuin- $\mathrm{A}$ and subclinical-clinical CVD-related complications [17, 18]. Trepanowski et al. reported fetuin-A is involved in the mechanism regulating the insulin downstream signaling pathway and acts as an inhibitor of insulin resistance in muscle, liver and fat [11]. Fetuin-knockout mice exhibit improved glucose and insulin tolerance and are resistant to high-fat diet-induced weight gain [19]. Although the regulation of fetuin-A synthesis is not completely understood, its strong association within metabolic diseases has made it an attractive target for the development of novel research approaches related to metabolic health, such as insulin sensitivity, glucose tolerance or circulating lipid level treatments.

In particular, fetuin-A is the contributor which plays a critical role in the impairment of two metabolic sensors, Sirtuin 1 and AMP-activated protein kinase, in inflamed adipocytes of high fat diet mice [20]. Several studies was proposed that increased circulating fetuin-A in humans after a chronic exercise program may promote increased weight loss and improved metabolic control through elevation of adiponectin expression [20] and decrease of inflammatory cytokines in the liver and muscle [21] via fetuin-A inhibition through the AMP-activated protein kinase-nuclear factor kappa-light-chain-enhancer of activated $B$ cells pathway [4]. Furthermore, fetuin-A directly correlated with two cardiometabolic risk markers, Apo B and C-reactive protein that, together with insulin resistance, are important components of the metabolic syndrome. This hypothesis seemed plausible, as studies demonstrated fetuin-A lowered expression of stimulated oxygen consumption and had an inverse association with blood postprandial insulin, c-peptide, and lipid peroxidation levels [21] and a positive association with adiponectin concentrations [22].

The exact role of exercise in regulating circulating fetuin-A concentration remains to be fully established. As a possible biological link between physical exercise and fetuin-A levels, cardiorespiratory fitness and muscular strength are inversely associated with liver fat and abdominal obesity [23, 24], and fetuin-A is associated with liver fat accumulation in humans [25]. A few studies have assessed the effects of lifestyle interventions such as hypocaloric diets [26] physical exercise [27, 28] or combined interventions [29] on fetuin-A, showing contradictory results. Some biological alterations promoting the protective effects of exercise on insulin sensitivity may be ex plained by changes in circulating fetuin-A and free fatty acids, supporting less toll-like receptor 4 signaling in adipose tissue perhaps by modulating adipose tissue macrophages [30]. In general, results on the effects of exercise on circulating fetuin-A have been rather ambiguous; diverse exercise amount and intensity within interventions may explain the highly discrepant results thus far.

In 2015, Trepanowski et al. [31] published the first comprehensive review to exclusively focus on the relationship between fetuin-A and obesity. To the best of the investigative team's knowledge, no systematic review, with or without meta-analysis, has analyzed the effects of exercise on fetuin-A levels in humans. Hence, the present work was undertaken [31]. Due to heterogeneity between studies in terms of results, we used a meta-analytic approach to determine the effectiveness of supervised exercise interventions on fetuin-A in adults.

\section{Methods}

\section{Protocol and registration}

The study was undertaken in accordance with the Preferred Reporting Items for Systematic Reviews and Meta -Analyses (PRISMA) statement [32]. The review was registered with PROSPERO (CRD42017073872) at the University of York, UK. However, no study protocol was published before the initiation of the meta-analysis. All analyses were based on aggregate data from previously published studies, and thus, no ethical approval was required.

\section{Eligibility criteria}

The a priori inclusion criteria for this study were as follows: (1) adults aged 18 years old; (2) interventions of physical exercise without hypocaloric diet intervention; and (3) assessment of serum fetuin-A.

\section{Information sources}

A search of the literature was performed using the electronic databases Cochrane Central Register of Controlled Trials (CENTRAL), EMBASE, and MEDLINE (all: from 1998 until 15 November 2017). The terms used were as follows: ['Fetuin-A and 'alpha2hsglycoprotein' OR], ['Exercise' and 'training' and 'physical activity' and 'sport' OR].

\section{Search}

Two researchers (AG-H and RR-V) independently carried out the search. As an example, the search strategy in MEDLINE database was as follows: "Fetuin-A and 
alpha2hsglycoprotein" AND "metabolic risk" OR "cardiometabolic risk" OR "type 2 diabetes" "metabolic syndrome" OR "obesity") AND ("exercise" OR "physical activity" OR "exercise intervention" OR "training") AND ("intervention" OR "program" OR "trial" OR "treatment" OR "pre-post study"). Additionally, the reference lists of retrieved studies were examined to identify other articles. Studies reported in languages other than English were not explored.

\section{Study selection}

Two authors (AG-H and RR-V) independently screened the titles and abstracts of potentially eligible studies identified by the search strategy. If necessary, a third researcher (MI) was consulted. The bibliographic management software EndNote version X7.0 for Windows was used for all searches. Any differences between the two authors were discussed and, if necessary, the third author was referred to for arbitration. Reasons for exclusion of identified articles were recorded in all cases.

\section{Data collection process and data items}

Two researchers (AG-H and RR-V) independently abstracted all data. For each study, data were extracted regarding the first author's last name, year of publication, characteristics of the subjects, exercise programs (type, frequency, duration, intensity, etc.), assessment of fetuin-A, sample size, and mean values with corresponding standard deviations of fetuin-A and BMI (pre- and post-test). The reviewers created a study-specific database in Excel (Microsoft Corp., USA) for data collection. Any differences between the two authors were discussed and, if necessary, the third author was referred to for arbitration.

\section{Risk of bias of individual studies}

The methodological quality of non-RCT studies and studies without a control group was assessed using the Quality Assessment Tool for Quantitative Studies of the Effective Public Health Practice Project (EPHPP) [33]. This tool is used to evaluate a variety of intervention study designs, such as non-RCT or pre-post studies [33]. EPHPP assesses study quality in six domains: selection bias, study design, confounders, blinding, data collection method, and withdrawals/dropouts. Each study was assessed for quality by 2 reviewers (AG-H and RR-V), and any discrepancy in the final grade was resolved through group discussion or discussion among the primary authors.

\section{Summary measures}

All analyses were carried out using Comprehensive Meta-analysis Software (second version, Biostat, Englewood, NJ, USA) to calculate the standardized mean difference and expressed as Hedges' g to correct for possible small-sample bias [34]. For studies that were randomized and non-randomized controlled trials, the Hedges' g was calculated taking the change outcome difference between the exercise and control groups and then dividing that difference by the pooled standard deviation of the change outcome difference. For single group studies, the Hedges' g value of the fetuin-A was calculated by the mean pre- to post-intervention in each study (i.e., in all cases the pre-intervention and the post-intervention data were used to meta-analyze), dividing the result by the pooled standard deviation, and correcting for small sample bias. We used the continuous random-effect analysis with the DerSimonian-Laird me thod to pool results. For studies where means and standard deviations were not reported and could not be obtained from the authors, we transformed dichotomous data into the standardized mean difference using the formulas implemented in Comprehensive Meta-analysis [35] or used other statistics, such as t-values or exact $p$-values to calculate the standardized mean difference. In the cumulative meta-analysis, outcome data for fetuin-A from all available studies were included sequentially according to the year in which they first became available.

\section{Synthesis of results}

Heterogeneity between trial results was tested with Cochran's Q test [34] and the $\mathrm{I}^{2}$ statistic. $\mathrm{I}^{2}$ values of $<$ $25 \%, 25-50$, and $>50 \%$ are considered to represent small, medium, and large amounts of inconsistency [36]. Each study was deleted from the model once to analyze its influence on the overall results.

\section{Risk of bias across studies}

Small-study effects was assessed in two ways: 1) visual inspection of the asymmetry of the funnel plot and Egger's test of the intercept to test the symmetry of the funnel plot [37].

\section{Additional analysis}

Subgroup analyses were conducted to determine whether fetuin-A differed according to population characteristics by stratifying the meta-analyses by each of these factors (i.e., healthy, type 2 diabetes/dysglycemia and obese) using the random-effect model. Additionally, random-effects meta-regression analyses were used to evaluate whether the results differed with BMI changes (as Hedges' g) [38]. The effect of individual studies on the pooled Hedges' g was assessed with influence analysis, in which the analysis was repeated omitting one study at a time, to establish the contribution of each study to the effect size. 


\section{Patient involvement}

Due to the nature of the study, no participants were involved in the systematic review and meta-analysis. Furthermore, no patients were involved in the development of the research question or outcome measures, nor were they involved in the design, implementation, recruitment, or conduct of the study. Finally, no patients were asked to advise on the interpretation or writing up of the results. There are no plans to disseminate the results of the research to the study participants.

\section{Results}

\section{Study selection}

A total of 189 studies were identified through the database search. The titles and abstracts of the returned articles were examined for suitability, leading to the retrieval of 23 full texts. Of those 13, 4 were rejected -3 because of the type of intervention criterion (interventions with hypocaloric diet), and one because of the population issues (adolescents). Nine trials met the inclusion criteria and were included in the meta-analysis [5, 21, 27-30, 39-41]. A flow diagram summarizing the study selection process of the systematic review and meta-analysis is shown in Fig. 1. Exclusion criteria and the list of excluded articles are in online Additional file 1.

The characteristics of the nine studies included in the systematic review sorted by study design are available in Table 1. All studies were single-group pre-post design except two randomized controlled trials $[40,41]$ and one a randomized trial without a control group [21]. A total of 163 individuals were included in the meta-analysis. Two studies included only women $[29,39]$, one included only men [30], and five included mixed samples of men and women $[5,21,27,28,40,41]$ who were relative healthy [30], were obese [21, 27-29, 39], suffered from nonalcoholic fatty liver disease [21, 28], or had type 2 diabetes/dysglycemia or were undergoing hemodialysis $[5,30,41]$.

Relative to exercise programs, all studies used aerobic exercise except two that used a combined aerobic plus resistance exercise protocol (concurrent exercise) [29, 30]. Overall, the programs mainly used treadmill walking/running, cycle ergometer cycling and whole-body resistance training. The study durations ranged from one to 16 weeks, and the training frequency ranged from three to seven times weekly with $40-70$ min session duration. All exercise interventions were supervised.

\section{Measurement of fetuin-a}

All studies measured fetuin-A using enzyme-linked immunosorbent assays (ELISA) according to the manufacturer's protocols.

\section{Risk of bias within studies}

Only three trials had random allocation between groups [21, 40, 41]. All studies provided points and estimates of variability. Blinding of the participants and therapists was not possible because of the nature of the interventions. The studies' "bias" score ranged from two to four with a mean total score of 2.62 .

\section{Synthesis of results}

Overall, supervised exercise training was associated with a significant reduction in the random-effects models ( $\mathrm{g}$ $=-0.640 ; 95 \% \mathrm{CI},-1.129$ to $-0.151 ; \mathrm{p}=0.010$ ) with high heterogeneity $\left(\mathrm{I}^{2}=87.60 \%\right)$ (Fig. 2).

\section{Risk of bias across studies}

Small-study effects by means of visual inspection of funnel plots was evaluated and the Egger's regression asymmetry test. As shown in Fig. 3, the funnel plot was symmetrical and Egger's linear regression tests provided no evidence for existence of small-study effects (Egger regression intercept, -4.42 [95\% CI, -8.44 to $0.11, p=$ $0.052])$.

\section{Additional analysis}

Regarding subgroup analysis, in obese individuals, physical exercise favored a reduction in fetuin-A the overall same effect was not observed in individuals with obesity $\left(\mathrm{g}=-0.096 ; 95 \% \mathrm{CI},-0.328\right.$ to $0.135 ; p=0.415 ; \mathrm{I}^{2}=$ $29.04 \%)$ and type 2 diabetes/dysglycemia $(g=-1.698$; $95 \% \mathrm{CI},-3.570$ to $\left.0.174 ; p=0.075 ; \mathrm{I}^{2}=94.24 \%\right)$. The independent effects of potential moderating variables were examined using meta-regression and are presented in Fig. 4. The meta-regression analysis shows that there was not a greater decrease in fetuin-A in individuals who achieved greater BMI changes. The slope regression coefficient was 0.065 [95\% CI, -0.185 to 0.315 ] and was not significant $(p=0.609)$.

Finally, the influence analysis showed that no particular trial affected the pooled effect size (Fig. 5).

\section{Discussion}

To our knowledge, this is the first systematic review and meta-analytic approach assessing the effects of supervised exercise training on fetuin-A in adults. The main findings of our study are as follows: (i) supervised exercise interventions is associated with reductions in fetuin-A in adults and older participants; (ii) both aerobic and resistance exercise at vigorous or moderate intensity, with a volume of $60 \mathrm{~min} / \mathrm{session}$ and a minimum frequency of 4 to 7 sessions/week, significantly reduced fetuin-A levels in dysglycemic and overweight/ obese individuals; and (iii) greater BMI reductions after the supervised exercise intervention are not associated with greater reductions in fetuin-A. These findings could 


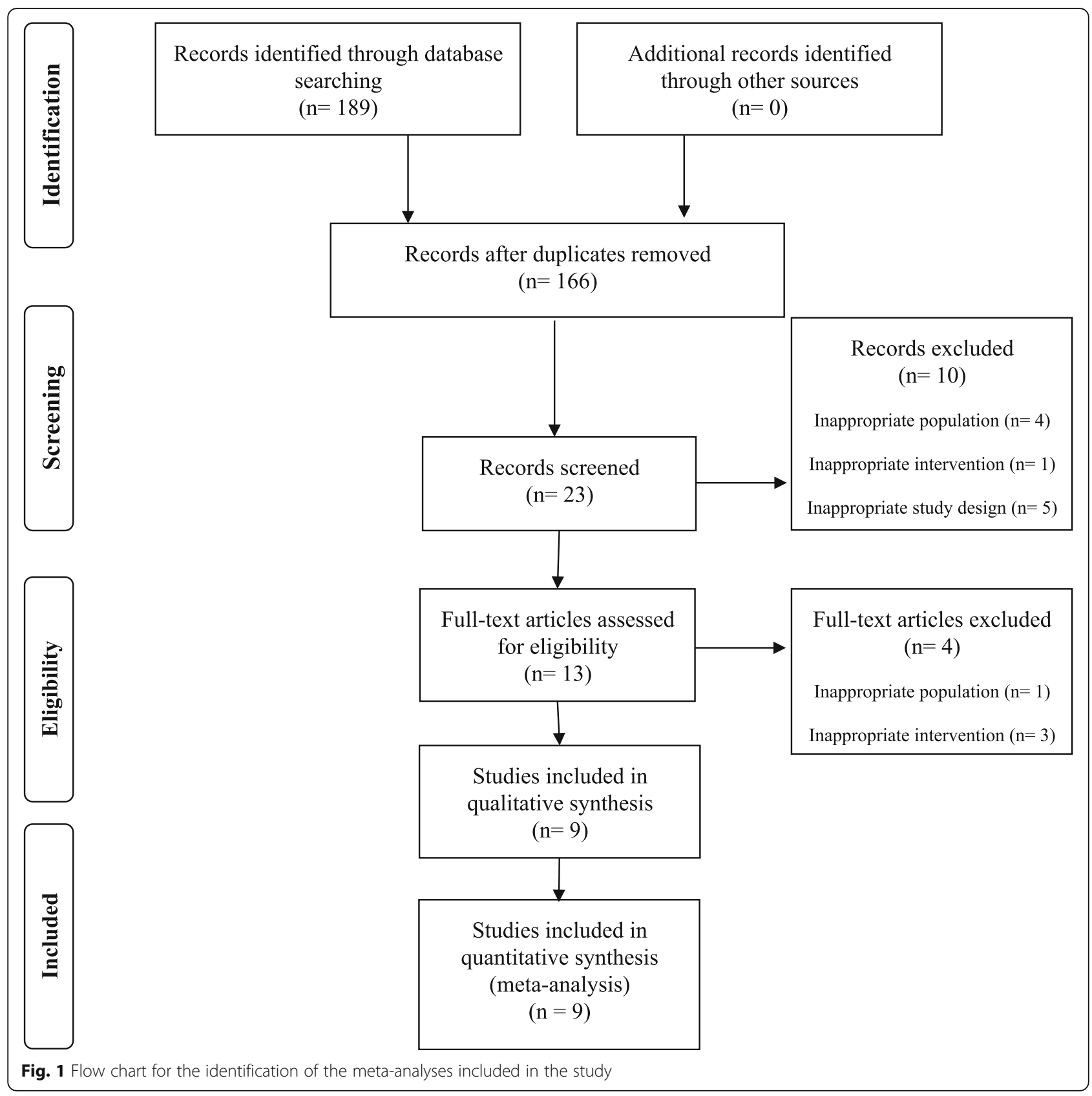

help to provide more specific exercise recommendations for cardiometabolic risk factor management in the adult population. However, due to population heterogeneity and the high risk of bias, our findings should be interpreted with caution.

Our results show that supervised exercise training alone is associated with reductions in fetuin-A levels in adults. This finding is consistent with recently published systematic reviews and meta-analyses showing that exercise significantly modulates adipokine levels, inflammatory cy tokine and glycemic control in youths [42] and patients with type 2 diabetes [30]. Jenkins et al. [43] have suggested an inverse correlation between cardiorespiratory fitness and fetuin-A, which would suggest that physical fitness level may regulate to some degree fetuin-A concentrations. However, in contrast with this conclusion, Malin et al., [27] showed that exercise-induced changes in fetuin-A were not associated with cardiorespiratory fitness in healthy adults. Two other narrative reviews [31, 44] also suggested that exercise alone might improve adipokine levels, such as fetuin-A. Our results show that supervised exercise training on fetuin-A was statistically significant when comparing post vs. pre-intervention values with large heterogeneity $\left(I^{2}=87.60 \%\right)$, even though some of the 
Table 1 Characteristics of the included trials

\begin{tabular}{|c|c|c|c|c|c|c|}
\hline Study and design & Sample & $\begin{array}{l}\text { Age } \\
\text { (years) }\end{array}$ & $\begin{array}{l}\text { Type of } \\
\text { exercise }\end{array}$ & $\begin{array}{l}\text { Exercise program } \\
\text { characteristics }\end{array}$ & $\begin{array}{l}\text { Reduced } \\
\text { Fetuin-A }\end{array}$ & EPHPP \\
\hline $\begin{array}{l}\text { Lee et al. } 2017 \text { [30] Single-group } \\
\text { pre-post design }\end{array}$ & $\begin{array}{l}26 \text { men (13 dysglycemic and } \\
\text { overweight) without CVD }\end{array}$ & 51.1 & Concurrent & $\begin{array}{l}\text { Total duration: } 12 \text { weeks } \\
\text { Frequency a week: } 4 \\
\text { sessions } \\
\text { Duration per session: 60-min } \\
\text { Aerobic; Intensity: NR } \\
\text { Resistance; Intensity: NR }\end{array}$ & Yes & 2 \\
\hline $\begin{array}{l}\text { Malin et al. } 2013 \text { [28] Single- } \\
\text { group pre-post design }\end{array}$ & $\begin{array}{l}13 \text { obese men and women with } \\
\text { nonalcoholic fatty liver disease } \\
\text { without CVD }\end{array}$ & 50.5 & Aerobic & $\begin{array}{l}\text { Total duration: } 1 \text { week } \\
\text { Frequency a week: } 5 \\
\text { sessions } \\
\text { Duration per session: } 60 \text {-min } \\
\text { Intensity: } 85 \% \text { HRmax }\end{array}$ & Yes & 2 \\
\hline $\begin{array}{l}\text { Malin et al. 2014[27] Single- } \\
\text { group pre-post design }\end{array}$ & $\begin{array}{l}20 \text { older obese men and women } \\
\text { without CVD }\end{array}$ & 66.3 & Aerobic & $\begin{array}{l}\text { Total duration: } 12 \text { weeks } \\
\text { Frequency a week: } 7 \\
\text { sessions } \\
\text { Duration per session: } 60 \text {-min } \\
\text { Intensity: } 85 \% \text { HRmax }\end{array}$ & Yes & 2 \\
\hline $\begin{array}{l}\text { Mori et al. 2008[5] Single-group } \\
\text { pre-post design }\end{array}$ & $\begin{array}{l}8 \text { men and women with type } 2 \\
\text { diabetes mellitus }\end{array}$ & 62.0 & Aerobic & $\begin{array}{l}\text { Total duration: } 12 \text { weeks } \\
\text { Frequency a week: } 3-5 \text { sessions } \\
\text { Duration per session: } 40-\mathrm{min} \\
\text { Intensity: } 103 \mathrm{bpm}\end{array}$ & No & 2 \\
\hline $\begin{array}{l}\text { Schultes et al. 2010[39] Single- } \\
\text { group pre-post design }\end{array}$ & $\begin{array}{l}14 \text { obese women and without } \\
\text { CVD }\end{array}$ & 43.2 & Aerobic & $\begin{array}{l}\text { Total duration: } 6 \text { weeks } \\
\text { Frequency a week: } 3 \text { sessions } \\
\text { Duration per session: } 60 \text {-min } \\
\text { Intensity: } 60 \% \text { VO2peak }\end{array}$ & No & 3 \\
\hline Wilund et al. 2010[40] RCT & 17 hemodialysis men and women & 59.9 & Aerobic & $\begin{array}{l}\text { Total duration: } 16 \text { weeks } \\
\text { Frequency a week: } 3 \\
\text { sessions } \\
\text { Duration per session: } 45 \text {-min } \\
\text { Intensity: rate of perceived } \\
\text { exertion of } 12-14\end{array}$ & No & 4 \\
\hline $\begin{array}{l}\text { Winn et al. } 2017 \text { [21] Randomized trial } \\
\text { without a control group }\end{array}$ & $\begin{array}{l}18 \text { obese men and women } \\
\text { without CVD }\end{array}$ & 51.4 & Aerobic & $\begin{array}{l}\text { Total duration: } 4 \text { weeks } \\
\text { Frequency a week: } 4 \\
\text { sessions } \\
\text { Duration per session: NR } \\
\text { Intensity: } 55 \% \text { VO2peak or } \\
\text { 80\% VO2peak }\end{array}$ & No & 5 \\
\hline $\begin{array}{l}\text { Yang et al. 2011[29] Single-group } \\
\text { pre-post design }\end{array}$ & 40 obese women without CVD & 45.3 & Concurrent & $\begin{array}{l}\text { Total duration: } 12 \text { weeks } \\
\text { Frequency a week: } 5 \\
\text { sessions } \\
\text { Duration per session: } 65 \text {-min } \\
\text { Aerobic; Intensity: } 60-75 \% \text { HRmax } \\
\text { Resistance; Intensity: NR }\end{array}$ & No & 2 \\
\hline Zhang et al. 2017 [41] RCT & $\begin{array}{l}32 \text { men and women with type } 2 \\
\text { diabetes mellitus }\end{array}$ & 47.2 & Aerobic & $\begin{array}{l}\text { Total duration: } 12 \text { weeks } \\
\text { Frequency a week: } 5 \text { sessions } \\
\text { Duration per session: } 70 \text {-min } \\
\text { Aerobic; Intensity: } 70 \% \text { HRmax }\end{array}$ & Yes & 4 \\
\hline
\end{tabular}

$\mathrm{Bpm}$ beats per minute, HRmax maximum heart rate.The methodological logical quality of non-randomized controlled trials and studies without control group $(N=$ 8) was assessed using the Quality Assessment Tool for Quantitative Studies of the Effective Public Health Practice Project (EPHPP) (6 evaluation critical methodological components). CVD, cardiovascular disease; RCT, randomised controlled trial

studies showed no changes after the exercise intervention. However, these results should be treated with caution given the limited number of studies included in our analysis. The differences between the results observed in the analyses examining the effect of exercise could be due to the large heterogeneity and lack of comparison with control groups. Also, these discrepancies can likely be explained by the wide range of characteristics of the participants ( $>50$ years old, diseases, etc.), study duration, intervention exercise program (i.e., cycling, treadmill and/ or elliptical, weight machines), and extent of change in body composition across these studies.

Fetuin-A may attenuate lipogenesis and accelerate lipolysis in adipocytes, thereby promoting obesity and insulin resistance [31]. Regarding both diseases and according to subgroup analysis (individuals with type 2 diabetes/dysglycemia or obese individuals), we found no evidence to support that supervised exercise was associated with a 
reduction in serum fetuin-A levels. Stefan and associates conducted a study involving a complex lifestyle intervention program including dietary counseling and increased physical activity and found different results. They reported body weight decreased by $\sim 3.2 \mathrm{~kg}$, liver fat by $34 \%$, and energy and, in particular, saturated fat intake by 7 and $11 \%$, respectively, and fetuin-A levels decreased over an 9-month period in subjects with a high risk for type 2 diabetes [45]. Recently, another randomized trial in obese adults confirm our findings and did not detect significant reductions in fetuin-A after applied two different exercise programs at moderate and high intensity [21]. Therefore, it is unclear whether these divergent findings are attributable to differences in the duration and intensity of the intervention, in health status, in the timing of fetuin-A measurement (e.g., within $24 \mathrm{~h}$ versus $36-48 \mathrm{~h}$ after the last exercise session), or in the sex of the participants; however, there is some evidence that relationships between fetuin-A levels and "outcomes" vs. "status" exist [45]. Reduced fetuin-A in response to intervention is often associated with improvement in insulin-related parameters [46], which was confirmed in all of the studies showing decreases in this hepatokine. For example, the study published by Lee et al. [30] demonstrated that changes in circulating fetuin-A might predict some of the benefits seen on insulin sensitivity after long-term exercise. Another study in older obese subjects also reveals that lower fetuin-A after exercise correlated with lower hepatic insulin resistance [27]. These authors suggest that fetuin-A down regulates glucose transporter- 4 translocation and contributes to the improvement in skeletal muscle glucose disposal after exercise.

The meta-regression analyses showed that there was not a greater decrease in fetuin-A in individuals who achieved greater BMI changes. These findings are partly in accordance with those reported in adults with different health statuses. For example, six weeks of supervised aerobic exercise showed modest changes in body composition without affecting serum fetuin-A levels in obese older women [39]; however, 12 weeks of aerobic-exercise with significant weight loss did reduce plasma fetuin-A levels in a study of obese older men and women [28]. Additionally, a recent review suggests that weight loss seems to be effective for reducing fetuin-A level, which is not consistent with our findings [31]. Some previous studies suggest that dietary changes and weight loss [47] as well as pharmacological treatment with thiazolidinediones [5] or metformin [48] might be more potent factors than aerobic exercise alone in the regulation of hepatic fetuin-A release. Hennige et al. [49] also suggested that fetuin-A induces low-grade inflammation and represses adiponectin production in animals and in humans. Collectively, it appears likely that hepatic fat content and thus serum fetuin-A levels respond to changes in energy balance rather than to changes in body composition [39]. These data suggest an important role of fatty liver in the pathophysiology of insulin resistance and atherosclerosis. In this context, the decrease in fetuin-A observed in the present study, along with changes in BMI, could be interpreted as overall beneficial to reduce CVD risk through supervised exercise training in humans. Nonetheless, the disparate findings suggest more research and comprehensive studies of changes in fetuin-A levels as a function of exercise interventions and body composition change appears necessary.

The current meta-analytic approach was not designed to establish the exact mechanism responsible for exercise reducing fetuin-A in humans, but our data indicate that exercise is associated with lower fetuin-A, as suggested previously by others [45]. The plausible mechanisms by which supervised exercise lowers fetuin-A include the following: (i) reducing intrahepatic fat content by down-re gulating sterol regulatory element-binding protein-1c and up-regulating peroxisome proliferator-activated receptor $\gamma$

\begin{tabular}{|c|c|c|c|c|c|c|c|c|c|}
\hline \multirow[t]{2}{*}{ Study name } & \multirow[t]{2}{*}{ Population } & \multirow[t]{2}{*}{$\underline{\text { Design }}$} & \multicolumn{7}{|c|}{$\underline{\text { Statistics for each study }}$} \\
\hline & & & $\begin{array}{l}\text { Hedges's } \\
\text { g }\end{array}$ & $\begin{array}{c}\text { Standard } \\
\text { error }\end{array}$ & Variance & $\begin{array}{c}\text { Lower } \\
\text { limit }\end{array}$ & $\begin{array}{c}\text { Upper } \\
\text { limit }\end{array}$ & Z-Value & p-Value \\
\hline Lee et al. $2017 \mathrm{a}$ & Healthy & Single group pre-post & -2.532 & 0.560 & 0.314 & -3.631 & -1.434 & 4.519 & 0.000 \\
\hline Lee et al. $2017 \mathrm{~b}$ & Dysglycemic & Single group pre-post & -3.753 & 0.781 & 0.609 & -5.283 & -2.223 & -4.809 & 0.000 \\
\hline Malin et al. 2013 & Obese & Single group pre-post & -0.059 & 0.260 & 0.068 & -0.568 & 0.450 & -0.227 & 0.820 \\
\hline Malin et al. 2014 & Obese & Single group pre-post & -0.355 & 0.222 & 0.049 & -0.790 & 0.080 & -1.600 & 0.110 \\
\hline Mori et al. 2008 & Type 2 Diabetes & Single group pre-post & 0.183 & 0.318 & 0.101 & -0.440 & 0.805 & 0.575 & 0.565 \\
\hline Schultes et al. 2010 & Obese & Single group pre-post & 0.000 & 0.252 & 0.063 & -0.493 & 0.493 & 0.000 & 1.000 \\
\hline Wilund et al. 2010 & Haemodialysis & RCT & -0.079 & 0.315 & 0.099 & -0.696 & 0.538 & -0.250 & 0.803 \\
\hline Winn et al. 2018 MCT & TObese & Randomized trial & -0.283 & 0.322 & 0.104 & -0.914 & 0.349 & -0.877 & 0.380 \\
\hline Winn et al. 2018 HIIT & Obese & Randomized trial & -0.499 & 0.338 & 0.114 & -1.162 & 0.163 & -1.477 & 0.140 \\
\hline Yang et al. 2011 & Obese & Single group pre-post & 0.214 & 0.157 & 0.025 & -0.093 & 0.522 & 1.366 & 0.172 \\
\hline Zhang et al. 2017 & Type 2 Diabetes & RCT & -1.859 & 0.289 & 0.084 & -2.427 & -1.292 & -6.424 & 0.000 \\
\hline & & & -0.640 & 0.249 & 0.062 & -1.129 & -0.151 & -2.567 & 0.010 \\
\hline
\end{tabular}

Fig. 2 Forest plot for changes in fetuin-A. The black horizontal lines represent the $95 \%$ confidence intervals while the squares represent the Hedge's g estimate. The first red diamond represents the overall point estimate and $95 \%$ confidence intervals from all individual studies included in each meta-analysis. All analyses are based on the random-effects model. RCT, randomized controlled trial 


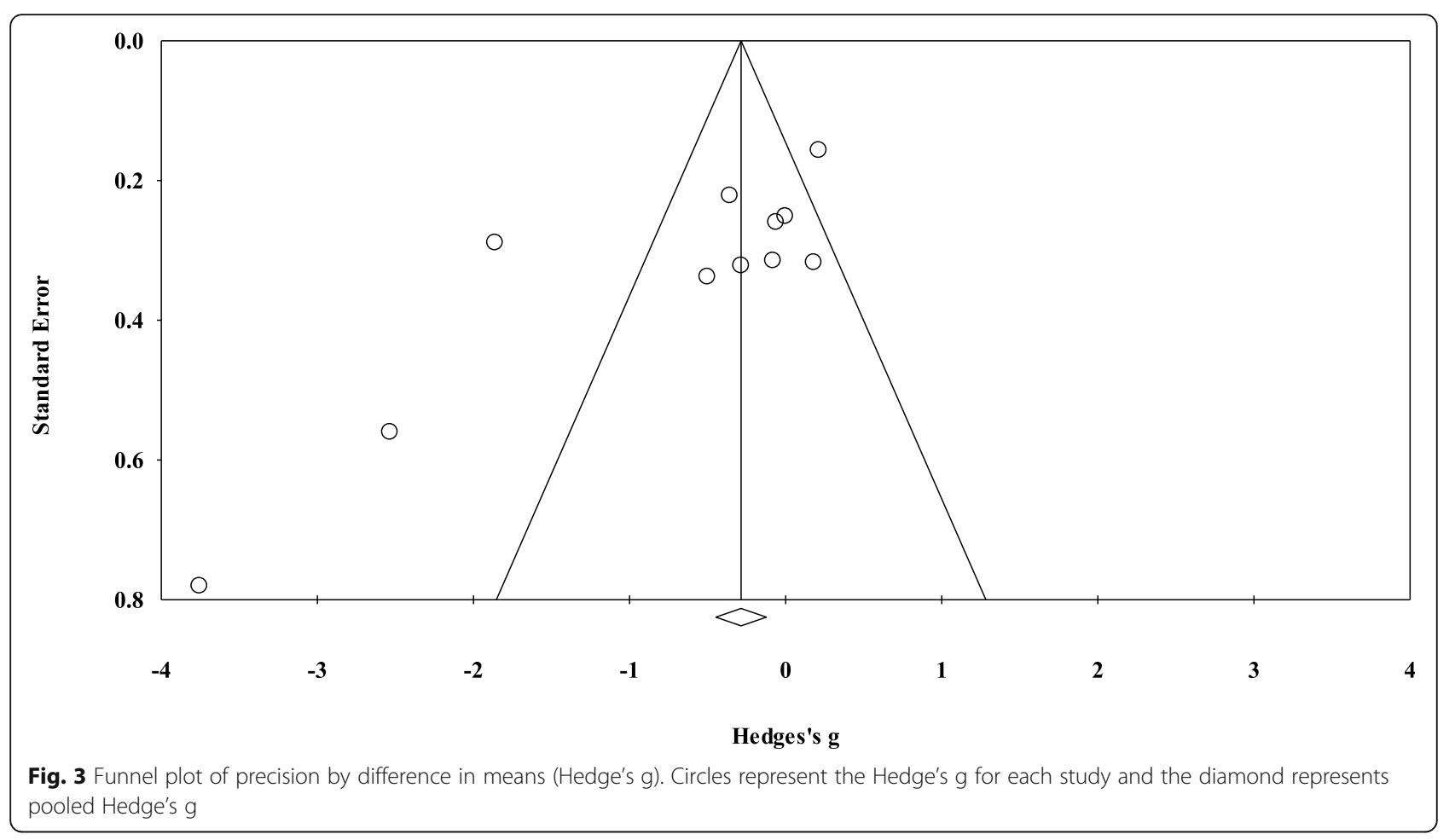

expression levels [50]; (ii) decreasing hepatic glucolipotoxicity through modulating the reactive oxygen species, along with inhibition of proinflammatory mediators [51]; and (iii) activating protein kinase B (also known as Akt) and Akt substrate of $160 \mathrm{kDa}$ (AS160) phosphorylation, which itself has been shown to improve glucose tolerance and decrease insulin resistance [52].

The current study has several limitations. First, we included both randomized controlled trials and clinical trials, which introduced some risk of bias [53]. Second, there is a high degree of heterogeneity among the analyzed studies, in part due to the differences in inclusion criteria, health status, and the type, intensity, and duration of the supervised-exercise interventions within individual studies. Third, meta-analysis and meta-regression analyses included a reduced number of studies, some of them with small sample sizes and control groups (no intervention). A high risk of bias (i.e., quality of the studies) could be considered another limitation. Fourth, since this was an aggregate data meta-analysis, the potential for ecological fallacy exists. Fifth, since studies are not randomly assigned to covariates in meta- analysis, they are considered to be observational in nature.

Consequently, the results of subgroup and meta-regression analyses conducted in our meta-analysis do not support causal inferences and should hence be viewed as

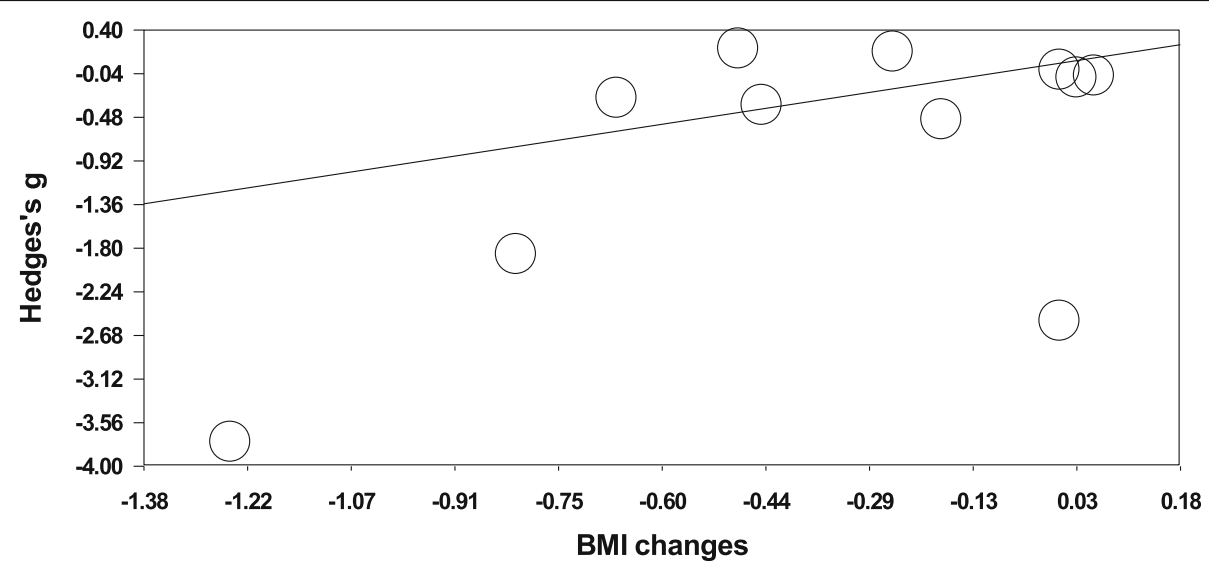

Fig. 4 Meta-regression analysis of changes in body mass index (BMI) ( $X$ axis) against the Hedges's $g$ fetuin-A levels ( $Y$ axis) 


\begin{tabular}{|c|c|c|c|c|c|c|c|c|c|c|c|c|c|c|}
\hline \multirow[t]{2}{*}{$\underline{\text { Study name }}$} & \multirow[t]{2}{*}{ Population } & \multirow[t]{2}{*}{ Design } & \multicolumn{7}{|c|}{ Statistics with study removed } & \multicolumn{5}{|c|}{ Hedges's g $(95 \%$ Cl) with study removed } \\
\hline & & & Point ${ }^{S}$ & $\begin{array}{l}\text { Standard } \\
\text { error }\end{array}$ & Variance & $\begin{array}{l}\text { Lower } \\
\text { limit }\end{array}$ & $\begin{array}{c}\text { Upper } \\
\text { limit }\end{array}$ & Z-Value & $\mathrm{p}$-Value & & & & & \\
\hline Lee et al. 2017a & Healthy & Single group pre-post & -0.478 & 0.236 & 0.056 & -0.940 & -0.015 & -2.026 & 0.043 & & & & & \\
\hline Lee et al. $2017 \mathrm{~b}$ & Dysglycemic & Single group pre-post & -0.452 & 0.226 & 0.051 & -0.895 & -0.009 & -2.001 & 0.045 & & & & & \\
\hline Malin et al. 2013 & Obese & Single group pre-post & -0.718 & 0.278 & 0.077 & -1.263 & -0.174 & -2.586 & 0.010 & & & & & \\
\hline Malin et al. 2014 & Obese & Single group pre-post & -0.693 & 0.285 & 0.081 & -1.252 & -0.135 & -2.433 & 0.015 & & & & & \\
\hline Mori et al. 2008 & Type 2 Diabetes & Single group pre-post & -0.733 & 0.270 & 0.073 & -1.262 & -0.204 & -2.718 & 0.007 & & & & & \\
\hline Schultes et al. 2010 & Obese & Single group pre-post & -0.725 & 0.278 & 0.077 & -1.270 & -0.181 & -2.610 & 0.009 & & & & & \\
\hline Wilund et al. 2010 & Haemodialysis & RCT & -0.709 & 0.273 & 0.075 & -1.245 & -0.174 & -2.598 & 0.009 & & & & & \\
\hline \multirow{2}{*}{\multicolumn{2}{|c|}{$\begin{array}{l}\text { Winn et al. } 2018 \text { MICTObese } \\
\text { Winn et al. } 2018 \text { HIIT Obese }\end{array}$}} & Randomized trial & -0.688 & 0.273 & 0.075 & -1.224 & -0.153 & -2.519 & 0.012 & & & & & \\
\hline & Obese & Randomized trial & -0.664 & 0.271 & 0.074 & -1.196 & -0.132 & -2.447 & 0.014 & & & & & \\
\hline \multirow{4}{*}{$\begin{array}{l}\text { Yang et al. } 2011 \\
\text { Zhang et al. } 2017\end{array}$} & Obese & Single group pre-post & -0.752 & 0.275 & 0.076 & -1.291 & -0.213 & -2.733 & 0.006 & & & & & \\
\hline & Type 2 Diabetes & RCT & -0.452 & 0.216 & 0.047 & -0.876 & -0.028 & -2.090 & 0.037 & & & & & \\
\hline & & & -0.640 & 0.249 & 0.062 & -1.129 & -0.151 & -2.567 & 0.010 & & & & | & | \\
\hline & & & & & & & & & & -6.00 & -3.00 & 0.00 & 3.00 & 6.00 \\
\hline
\end{tabular}

association. Large, well- designed randomized controlled trials are needed to address this issue adequately. Given the former, future randomized controlled trials may want to address some of the differences and associations observed in our current meta-analysis. In the same line, future RCT studies would need to account for baseline levels, change in other cardiometabolic traits in addition to change in BMI, and effect of medication status, alcohol and smoking patterns, and diet patterns throughout the study period. Finally, since we ran a number of analyses, some of our findings could have been nothing more than chance occurrence. Therefore, the results should be taken with caution, and more research on the effect of exercise interventions is needed to reinforce the current recommendation on exercise in the regulation of hepatic fetuin-A in humans.

\section{Conclusions}

This meta-analysis shows that supervised exercise alone is associated with reductions in fetuin-A levels in adults and older participants. However, high quality randomized controlled trials describing the effects of supervised exercise interventions on fetuin- $\mathrm{A}$ in adults are few. Here in we have identify important components for future research that should be addressed as well as the limitations found in reviewing the studies for our analysis. By doing so, we hope to advance this area of research and aid in the answering of questions on exercise, hepatokines, and health, an area that is growing in interest and importance.

\section{Additional file}

Additional file 1: List of articles excluded after full text review with reasons for exclusion. (DOCX $20 \mathrm{~kb}$ )

\section{Abbreviations}

Bpm: Beats per minute; CVD: Cardiovascular disease; EPHPP: Effective Public Health Practice Project; HRmax: Maximum heart rate; PRISMA: Preferred
Reporting Items for Systematic Reviews and Meta-Analyses; RCT: Randomized controlled trial

Acknowledgements

Not applicable.

Funding

Not applicable.

Availability of data and materials

The dataset supporting the conclusions of this article is included within the article.

\section{Authors' contributions}

The contribution of each author for this paper was as follows, RR-V, AG-H and $\mathrm{Ml}$ designed the experimental study. RR-V and MI provide technical assistance regarding research and data interpretation. AC-H helped for drafting the manuscript. It is evident that all authors read and approved the final manuscript.

Ethics approval and consent to participate

Not applicable.

Consent for publication

Not applicable.

\section{Competing interests}

The authors declare that they have no competing interests.

\section{Publisher's Note}

Springer Nature remains neutral with regard to jurisdictional claims in published maps and institutional affiliations.

\section{Author details}

${ }^{1}$ Centro de Estudios para la Medición de la Actividad Física CEMA, Escuela de Medicina y Ciencias de la Salud, Universidad del Rosario, Bogotá 111221, Colombia. ${ }^{2}$ Laboratorio de Ciencias de la Actividad Física, el Deporte y la Salud, Facultad de Ciencias Médicas, Universidad de Santiago de Chile, USACH, 7500618 Santiago, Chile. ${ }^{3}$ Department of Exercise and Sport Science, University of North Carolina, Chapel Hill, North Carolina, USA. ${ }^{4}$ Department of Health Sciences, Public University of Navarre, CIBERFES (CB16/10/00315),

Pamplona, Navarre, Spain.

Received: 16 May 2018 Accepted: 6 January 2019

Published online: 22 January 2019

References

1. Pedersen KO. Fetuin, a new globulin isolated from serum. Nature. 1944; 154(3914):575

2. Mori K, Emoto M, Inaba M. Fetuin-A: a multifunctional protein. Recent Pat Endocr Metab Immune Drug Discov. 2011;5(2):124-46. 
3. Iroz A, Couty J-P, Postic C. Hepatokines: unlocking the multi-organ network in metabolic diseases. Diabetologia. 2015;58(8):1699-703.

4. Jung TW, Youn B-S, Choi HY, Lee SY, Hong HC, Yang SJ, et al. Salsalate and adiponectin ameliorate hepatic steatosis by inhibition of the hepatokine fetuin-a. Biochem Pharmacol. 2013;86(7):960-9.

5. Mori K, Emoto M, Araki T, Yokoyama H, Lee E, Teramura M, et al. Effects of pioglitazone on serum fetuin-a levels in patients with type 2 diabetes mellitus. Metabolism. 2008;57(9):1248-52.

6. Sun Q, Cornelis MC, Manson JE, Hu FB. Plasma levels of fetuin-a and hepatic enzymes and risk of type 2 diabetes in women in the US. Diabetes. 2013; 62(1):49-55.

7. Laugsand LE, Ix JH, Bartz TM, Djousse L, Kizer JR, Tracy RP, et al. Fetuin-a and risk of coronary heart disease: a Mendelian randomization analysis and a pooled analysis of AHSG genetic variants in 7 prospective studies. Atherosclerosis. 2015;243(1):44-52.

8. Aroner SA, St-Jules DE, Mukamal KJ, Katz R, Shlipak MG, Criqui MH, et al. Fetuin-a, glycemic status, and risk of cardiovascular disease: the multi-ethnic study of atherosclerosis. Atherosclerosis. 2016;248:224-9.

9. Laughlin GA, Barrett-Connor E, Cummins KM, Daniels LB, Wassel CL, IX JH. The Sex-specific association of fetuin-a with type 2 diabetes in older community-dwelling adults: the rancho Bernardo study. Diabetes Care. 2013;36(7):1994-2000.

10. Ix JH, Shlipak MG, Brandenburg VM, Ali S, Ketteler M, Whooley MA. Association between human fetuin-a and the metabolic syndrome: data from the heart and soul study. Circulation. 2006;113(14):1760-7.

11. Temesszentandrási G, Vörös K, Böröcz Z, Kaszás E, Prohászka Z, Falus A, et al. Association of human fetuin-a rs 4917 polymorphism with obesity in 2 cohorts. J Investig Med. 2015;63(3):548-53.

12. Weikert C, Stefan N, Schulze MB, Pischon T, Berger K, Joost H-G, et al. Plasma fetuin-a levels and the risk of myocardial infarction and ischemic stroke. Circulation. 2008;118(24):2555-62.

13. Mukhopadhyay S, Bhattacharya S. Plasma fetuin-a triggers inflammatory changes in macrophages and adipocytes by acting as an adaptor protein between NEFA and TLR-4. Diabetologia. 2016;59(4):859-60.

14. Pal D, Dasgupta S, Kundu R, Maitra S, Das G, Mukhopadhyay S, et al. Fetuina acts as an endogenous ligand of TLR4 to promote lipid-induced insulin resistance. Nature Med. 2012;18(8):1279-85.

15. Mathews ST, Rakhade S, Zhou X, Parker GC, Coscina DV, Grunberger G. Fetuin-null mice are protected against obesity and insulin resistance associated with aging. Biochem Biophys Res Commun. 2006;350(2):437-43.

16. Ou H-Y, Yang Y-C, Wu H-T, Wu J-S, Lu F-H, Chang C-J. Increased fetuin-a concentrations in impaired glucose tolerance with or without nonalcoholic fatty liver disease, but not impaired fasting glucose. J Clin Endocrinol Metab. 2012;97(12):4717-23.

17. Jung TW, Yoo HJ, Choi KM. Implication of hepatokines in metabolic disorders and cardiovascular diseases. BBA Clin. 2016;5:108-13.

18. Mori K, Emoto M, Inaba M. Fetuin-A and The cardiovascular system. Adv Clin Chem. 2012;56:175-95.

19. Oh K-J, Lee D, Kim W, Han B, Lee S, Bae K-H. Metabolic adaptation in obesity and type II diabetes: myokines, adipokines and hepatokines. Int J Mol Sci. 2016;18(1).

20. Chattopadhyay M, Mukherjee S, Chatterjee SK, Chattopadhyay D, Das S, Majumdar SS, et al. Impairment of energy sensors, SIRT1 and AMPK, in lipid induced inflamed adipocyte is regulated by Fetuin a. Cell Signal. 2018;42:67-76.

21. Winn NC, Liu Y, Rector RS, Parks EJ, Ibdah JA, Kanaley JA. Energy-matched moderate and high intensity exercise training improves nonalcoholic fatty liver disease risk independent of changes in body mass or abdominal adiposity—a randomized trial. Metabolism. 2017;78:128-40.

22. Blumenthal JB, Gitterman A, Ryan AS, Prior SJ. Effects of exercise training and weight loss on plasma Fetuin-a levels and insulin sensitivity in overweight older men. J Diabetes Res. 2017;2017:1492581.

23. Church TS, Kuk JL, Ross R, Priest EL, Biltoff E, Blair SN. Association of cardiorespiratory fitness, body mass index, and waist circumference to nonalcoholic fatty liver disease. Gastroenterology. 2006;130(7):2023-30

24. Pietiläinen KH, Kaprio J, Borg P, Plasqui G, Yki-Järvinen H, Kujala UM, et al. Physical inactivity and obesity: a vicious circle. Obesity. 2008;16(2):409-14.

25. Stefan N, Kantartzis K, Häring H-U. Causes and metabolic consequences of fatty liver. Endocr Rev. 2008;29(7):939-60.

26. König D, Zdzieblik D, Deibert P, Berg A, Gollhofer A, Büchert M. Internal fat and cardiometabolic risk factors following a meal-replacement regimen vs. comprehensive lifestyle changes in obese subjects. Nutrients. 2015;7(12):9825-33.
27. Malin SK, Del Rincon JP, Huang H, Kirwan JP. Exercise-induced lowering of fetuin-a may increase hepatic insulin sensitivity. Med Sci Sports Exerc. 2014; 46(11):2085-90,

28. Malin SK, Mulya A, Fealy CE, Haus JM, Pagadala MR, Scelsi AR, et al. Fetuin-a is linked to improved glucose tolerance after short-term exercise training in nonalcoholic fatty liver disease. J Appl Physiol. 2013;115(7):988-94.

29. Yang SJ, Hong HC, Choi HY, Yoo HJ, Cho GJ, Hwang TG, et al. Effects of a three-month combined exercise programme on fibroblast growth factor 21 and fetuin-a levels and arterial stiffness in obese women. Clin Endocrinol. 2011;75(4):464-9.

30. Lee S, Norheim F, Gulseth HL, Langleite TM, Kolnes KJ, Tangen DS, et al. Interaction between plasma fetuin-a and free fatty acids predicts changes in insulin sensitivity in response to long-term exercise. Physiol Rep. 2017;5(5).

31. Trepanowski J, Mey J, Varady K. Fetuin-a: a novel link between obesity and related complications. Int J Obes. 2015;39(5):734-41.

32. Liberati A, Altman DG, Tetzlaff J, Mulrow C, Gøtzsche PC, loannidis JP, et al. The PRISMA statement for reporting systematic reviews and meta-analyses of studies that evaluate health care interventions: explanation and elaboration. PLoS Med. 2009;6(7):e1000100.

33. Armijo-Olivo S, Stiles CR, Hagen NA, Biondo PD, Cummings GG. Assessment of study quality for systematic reviews: a comparison of the Cochrane collaboration risk of Bias tool and the effective public health practice project quality assessment tool: methodological research. J Eval Clin Pract. 2012;18(1):12-8.

34. Higgins JP, Thompson SG, Deeks JJ, Altman DG. Measuring inconsistency in meta-analyses. BMJ. 2003;327(7414):557.

35. Borenstein M, Hedges LV, Higgins JP, Rothstein HR. A basic introduction to fixed-effect and random-effects models for meta-analysis. Res Synth Methods. 2010;1(2):97-111.

36. Higgins JP, Thompson SG. Quantifying heterogeneity in a meta-analysis. Stat Med. 2002;21(11):1539-58.

37. Egger M, Smith GD, Schneider M, Minder C. Bias in meta-analysis detected by a simple, graphical test. BMJ. 1997;315(7109):629-34.

38. Thompson SG, Sharp SJ. Explaining heterogeneity in meta-analysis: a comparison of methods. Stat Med. 1999;18(20):2693-708.

39. Schultes B, Frick J, Ernst B, Stefan N, Fritsche A. The effect of 6-weeks of aerobic exercise training on serum fetuin-a levels in non-diabetic obese women. Exp Clin Endocrinol Diabetes. 2010;118(10):754-6.

40. Wilund KR, Tomayko EJ, Wu P-T, Ryong Chung H, Vallurupalli S, Lakshminarayanan B, et al. Intradialytic exercise training reduces oxidative stress and epicardial fat: a pilot study. Nephrol Dial Transplant. 2010;25(8): 2695-701.

41. Zhang L-Y, Liu T, Teng Y-Q, Yao X-Y, Zhao T-T, Lin L-Y, et al. Effect of a 12week aerobic exercise training on serum fetuin-a and adipocytokine levels in type 2 diabetes. Exp Clin Endocrinol Diabetes. 2017;126(08):487-92.

42. García-Hermoso A, Ceballos-Ceballos R, Poblete-Aro C, Hackney A, Mota J, Ramírez-Vélez R. Exercise, adipokines and pediatric obesity: a meta-analysis of randomized controlled trials. Int J Obes. 2017:41(4):475-82.

43. Jenkins NT, McKenzie JA, Hagberg JM, Witkowski S. Plasma fetuin-a concentrations in young and older high-and low-active men. Metabolism. 2011;60(2):265-71.

44. Pedersen BK. Anti-inflammatory effects of exercise: role in diabetes and cardiovascular disease. Eur J Clin Investig. 2017;47(8):600-11.

45. Stefan N, Hennige AM, Staiger H, Machann J, Schick F, Kröber SM, et al. a2Heremans-Schmid glycoprotein/fetuin-a is associated with insulin resistance and fat accumulation in the liver in humans. Diabetes Care. 2006;29(4):853-7.

46. Srinivas $P$, Wagner AS, Reddy LV, Deutsch D, Leon MA, Goustin AS, et al. Serum alpha 2-HS-glycoprotein is an inhibitor of the human insulin receptor at the tyrosine kinase level. Mol Endocrinol. 1993;7(11):1445-55.

47. Brix JM, Stingl H, Höllerl F, Schernthaner GH, Kopp H-P, Schernthaner G. Elevated Fetuin-a concentrations in morbid obesity decrease after dramatic weight loss. J Clin Endocrinol Metab. 2010;95(11):4877-81.

48. Haukeland JW, Dahl TB, Yndestad A, Gladhaug IP, Løberg EM, Haaland T, et al. Fetuin a in nonalcoholic fatty liver disease: in vivo and in vitro studies. Eur J Endocrinol. 2012;166(3):503-10.

49. Hennige AM, Staiger H, Wicke C, Machicao F, Fritsche A, Häring H-U, et al. Fetuin-a induces cytokine expression and suppresses adiponectin production. PLoS One. 2008;3(3):e1765.

50. González-Ruiz K, Ramirez-Velez R, Correa-Bautista JE, Peterson MD, GarciaHermoso A. The effects of exercise on abdominal fat and liver enzymes in pediatric obesity: a systematic review and meta-analysis. Child Obes. 2017. 13(4):272-82. 
51. Guo R, Liong EC, So KF, Fung M-L, Tipoe GL. Beneficial mechanisms of aerobic exercise on hepatic lipid metabolism in non-alcoholic fatty liver disease. Hepatobiliary Pancreat Dis Int. 2015;14(2):139-44.

52. Xu XJ, Valentine RJ, Ruderman NB. AMP-activated protein kinase (AMPK): does this master regulator of cellular energy state distinguish insulin sensitive from insulin resistant obesity? Curr Obes Rep. 2014;3(2):248-55.

53. Sacks H, Chalmers TC, Smith H Jr. Randomized versus historical controls for clinical trials. Am J Med. 1982;72(2):233-40

Ready to submit your research? Choose BMC and benefit from:

- fast, convenient online submission

- thorough peer review by experienced researchers in your field

- rapid publication on acceptance

- support for research data, including large and complex data types

- gold Open Access which fosters wider collaboration and increased citations

- maximum visibility for your research: over $100 \mathrm{M}$ website views per year

At $\mathrm{BMC}$, research is always in progress.

Learn more biomedcentral.com/submissions 